\title{
Kelayakan Finansial Fasilitas Parkir Pasar Aceh Berdasarkan Qanun Kota Banda Aceh
}

\author{
Rahmat Djamaluddin**1, Edi Mawardi ${ }^{2}$ \\ 1,2 Jurusan Teknik Sipil Universitas Teuku Umar, Alue Penyareng, Meulaboh 23615 \\ e-mail : ${ }^{* 1}$ rahmatdj.78@gmail.com, ${ }^{2}$ eddy_melbon@yahoo.com
}

\begin{abstract}
Abstrak
Gedung Parkir Pasar Aceh Baru merupakan salah satu tempat fasilitas parkir didalam gedung pasar Aceh Baru (Off Street Parking). Dengan meningkatnya pengunjung ke Pasar Aceh Baru maka kebutuhan akan tempat parkir juga semakin meningkat. Dalam hal ini penulis ingin menganalisa kelayakan dari segi finasial berdasarkan tarif parkir yang menggunakan Qanun Kota Banda Aceh No 4 Tahun 2012. Tujuan penelitian adalah menghitung jumlah kendaraan yang parkir, akumulasi kendaraan dan melihat tingkat kelayakan finansial dari fasilitas parkir tersebut berdasarkan Qanun Kota Banda Aceh No 4 Tahun 2012, sehingga diperoleh hasil kapan fasilitas parkir tersebut mengalami periode titik balik pengembalian modal (Payback Period). Penelitian ini menggunakan 3 Metode yaitu yaitu NPV, BCR dan IRR serta tingkat discount rate 10\%, 12\%, 15\% dan 18\%. Dari pengolahan data menggunakan 3 metode tersebut diperoleh hasil Net Present Value (NPV) terbesar senilai Rp. -3.853.539.000,- pada discount rate 10\% sedangkan Benefit Cost Ratio (BCR) sebesar 0,809 pada discount rate $10 \%$ serta nilai IRR sebesar :-1,149\%. Hal ini membuktikan bahwa dengan tarif parkir menggunakan Qanun Kota Banda Aceh No 4 Tahun 2012 fasilitas parkir tersebut tidak layak dibangun secara finansial.
\end{abstract}

Kata Kunci : Kelayakan Finansial, Tarif Parkir, NPV, BCR, dan IRR

\begin{abstract}
Off Street Parking building in Pasar Aceh Baru is one of the parking facilities available in the area. With the increase of visitors to Pasar Aceh Baru, the need for parking space is also increasing. In this case the authors want to analyze the feasibility in terms of finance based on parking rates using Qanun Banda Aceh City No. 4 year 2012. The objective of the study is to calculate the number of parking vehicles, vehicles accumulation and to see the financial feasibility level of the parking facilities based on Laws Banda Aceh city regulated by Qanun No. 4 year 2012, so the results obtained when the parking facility has a period of turnover point of payback (Payback Period). This study uses 3 methods, namely NPV, BCR and IRR and discount rate of 10\%, $12 \%, 15 \%$ and $18 \%$. From the data processing using 3 methods, resulted in Net Present Value (NPV) largest value is Rp. -3,853,539,000, - at 10\% discount rate while the Benefit Cost Ratio (BCR) is 0,809 at discount rate $10 \%$ and IRR value equal to $-1,149 \%$. This proves that with parking rates using Qanun Banda Aceh City No. 4 year 2012 the parking facilities are not feasible to be built financially.
\end{abstract}

Keywords: Financial Feasibility, Parking Rates, NPV, BCR, and IRR 


\section{PENDAHULUAN}

$\mathrm{B}_{\mathrm{s} a}^{\mathrm{a}}$ anda Aceh sebagai ibukota Provinsi Aceh merupakan pusat administrasi pemerintahan dan jasa serta pusat pendidikan yang mulai berkembang. Sebagai kota yang berkembang dengan pesat, kota Banda Aceh dituntut untuk bisa memberikan pelayanan yang baik bagi penduduknya. Salah satunya adalah dengan dibangunnya Gedung Pasar Aceh Baru. Gedung Pasar Aceh Baru diyakini merupakan sebagai pusat tarikan terbesar di kota Banda Aceh sehingga terjadi arus lalu lintas yang luar biasa padat baik pagi, siang, sore, maupun di malam hari. Masalah yang paling umum kita lihat adalah ketidakteraturan dalam menangani masalah perparkiran.

Hal inilah yang membuat Pemerintah Kota Banda Aceh membangun Gedung Pasar Aceh Baru lengkap dengan fasilitas parkir. Analisis permasalahan fasilitas parkir Gedung Pasar Aceh Baru ini ditinjau dari segi kelayakan finansial. Metode analisis yang digunakan adalah Metode Net Present Value (NPV), Benefit Cost Ratio (BCR) dan Internal Rate of Return (IRR). Analisis kelayakan finansial ini diharapkan dapat membantu pemerintah kota Banda Aceh agar dapat melihat kapan tingkat pengembalian modal (Payback Period).

[1] mendefinisikan parkir adalah tempat khusus bagi kendaraan untuk berhenti demi keselamatan. Ruang lain dapat digunakan untuk tempat parkir. Parkir mempunyai tujuan yang baik, akses yang mudah jika seseorang tidak dapat memarkir kendaraannya, dia tidak bisa membuat perjalanan. Analisis kebutuhan parkir merupakan suatu tugas yang sulit karena berbagai faktor yang mempengaruhi kebutuhan itu saling terkait [2].

Penetapan harga jasa fasilitas parkir akan berbeda untuk masing masing wilayah. Untuk menetapkan harga jasa fasilitas parkir tersebut adalah tergantung pada harga fasilitas parkir. Penetapan harga atas fasilitas parkir (tarif) selalu berpedoman kepada hukum penawaran dan permintaan [3]. Secara umum sistem penetapan tarif parkir adalah sebagai berikut:

1. Sistem tetap

2. Sistem berubah sesuai waktu (Progressif)

3. Sistem kombinasi

Dengan dibangunnya fasilitas parkir ini diharapkan dapat menampung semua jumlah kendaraan yang masuk ke dalam Gedung Pasar Aceh Baru sehingga dapat mengurangi kemacetan lalu lintas pada daerah ini. Fasilitas parkir ini juga ditujukan untuk menekan agar tidak ada lagi kendaraan yang menggunakan badan jalan sebagai lahan parkir seperti yang terjadi selama ini.

\section{METODE PENELITIAN}

Metode Penelitian ini diawali dengan pengumpulan data primer dan data sekunder. Setiap tahapan yang dilaksanakan dalam penelitian ini terdapat keterkaitan antara tahap yang satu dengan tahap yang lainnya untuk mendapatkan satu tujuan yang diinginkan. Data primer yang diambil adalah data jumlah kendaraan yang parkir selama seminggu pada kawasan Gedung Pasar Aceh Baru sedangkan data sekunder yang diambil adalah data RAB dan gambar desain gedung parkir Pasar Aceh Baru. Setelah data primer dan data sekunder dikumpulkan, selanjutnya dilakukan pengolahan data. Pada tahapan ini penulis mengumpulkan semua data baik data primer maupun data sekunder. Data yang diolah dibagi menjadi dua bagian yaitu : data biaya (cost) dan data manfaat (benefit). Data diolah dengan menggunakan aplikasi Microsoft Excell untuk mendapatkan jumlah kendaraan yang parkir sehingga didapat pendapatan parkir yang sesuai dengan tarif parkir berdasarkan Qanun Kota Banda Aceh No. 4 Tahun 2012 tentang Retribusi Pelayanan Parkir di Tepi Jalan Umum dengan sistem tarif parkir tetap yang menjadi nilai manfaat (benefit), sedangkan nilai biaya (cost) langsung diambil dari biaya konstruksi dari gedung fasilitas parkir, biaya pemeliharaan dan biaya operasional gedung parkir tersebut.

Analisis perhitungan pendapatan parkir dilakukan menggunakan rumus [4] yaitu : 
Vol. 4 No.1 April 2018

pp. 1 - 11

PPhr : JKP x Fp x Tp

Dimana :

PPhr : Pendapatan rata-rata dari parkir / hari

JKP : Jumlah kendaraan yang masuk kedalam gedung parkir dalam satu hari

Fp : Faktor Penggunaan

TP : Tarif Parkir

Dalam penelitian ini analisis pendapatan parkir dihitung perminggu karena data jumlah kendaraan rata-rata yang parkir dihitung selama seminggu. Pendapatan parkir perminggu ini dikalikan jumlah minggu dalam setahun. Hal ini dilakukan untuk mendapat nilai pendapatan parkir pertahun ditambah dengan tingkat pertumbuhan kendaaran yang parkir setiap tahunnya. Karena tarif parkir yang digunakan adalah tarif parkir berdasarkan Qanun Kota Banda Aceh No. 4 tahun 2012 yaitu tarif parkir tetap (fixed fare system), maka faktor penggunaan parkir (Fp) dianggap satu. Setelah mendapatkan data biaya (cost) dan data manfaat (benefit) selanjutnya dihitung aliran kas (cash flow) menggunakan Metode Net Present Value (NPV), Metode Benefit Cost Ratio (BCR) dan Metode Internal Rate of Return (IRR) dengan tingkat suku bunga (discount rate) sebesar 10\%, $12 \%, 15 \%$ dan $18 \%$ pertahun. Semua metode kelayakan finansial ini bertujuan untuk mendapatkan informasi kelayakan finansial dan tahun keberapa terjadinya titik pengembalian modal (Payback Period).

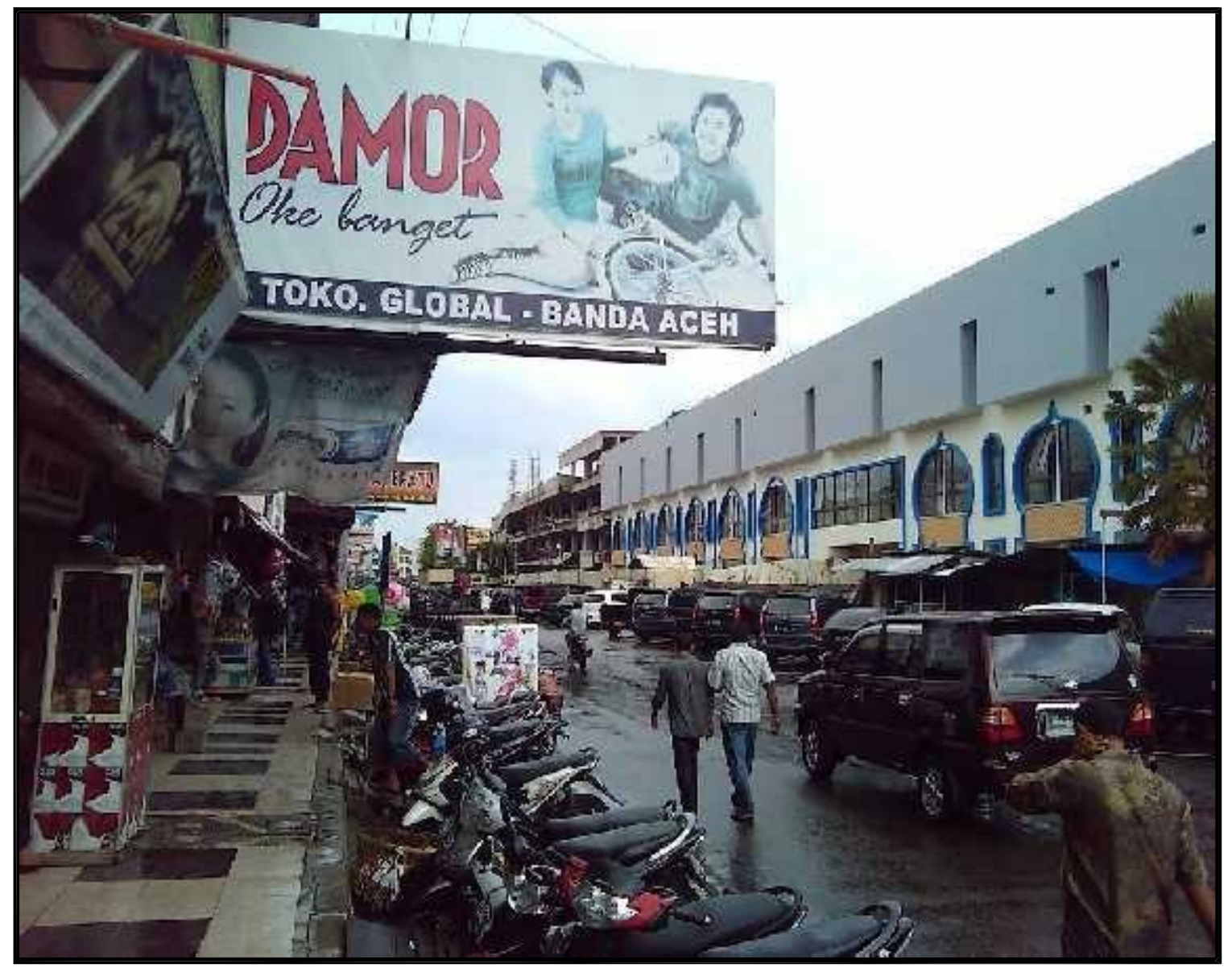

Gambar 1. Pengambilan Data 
Vol. 4 No.1 April 2018

pp. 1 - 11

\section{HASIL DAN PEMBAHASAN}

Dari hasil survey dilapangan diperoleh data primer untuk dijadikan sebagai manfaat (benefit) dari analisis kelayakan finasial ini adalah :

\section{Jumlah kendaraan parkir}

Tabel 1 Jumlah Kendaraan yang Parkir dalam Seminggu (Jl. Diponegoro)

\begin{tabular}{|c|c|c|c|c|c|}
\hline \multirow{2}{*}{ No } & \multirow{2}{*}{ Waktu (Pe riode) } & \multicolumn{4}{|c|}{ Jumlah Ke ndaraan (Unit) } \\
\hline & & \multicolumn{2}{|c|}{ Roda 2} & \multicolumn{2}{|c|}{ Roda 4} \\
\hline 1 & $06.00-10.00$ & 706 & Kend & 157 & Kend \\
\hline 2 & $10.00-14.00$ & 1.237 & Kend & 286 & Kend \\
\hline 3 & $14.00-18.00$ & 979 & Kend & 280 & Kend \\
\hline 4 & $18.00-22.00$ & 143 & Kend & 28 & Kend \\
\hline & Jumlah Total & 3.065 & Kend & 751 & Kend \\
\hline
\end{tabular}

Tabel 2 Jumlah Kendaraan yang Parkir dalam Seminggu (Jl. Diponegoro)

\begin{tabular}{r|r|r|r|r|r}
\hline \multirow{2}{*}{ No } & Waktu (Pe riode) & \multicolumn{2}{c}{ Jumlah Ke ndaraan (Unit) } \\
\hline 1 & $06.00-10.00$ & 2.064 & Kend & \multicolumn{1}{c}{ Roda 4} \\
\hline 2 & $10.00-14.00$ & 5.789 & Kend & 469 & Kend \\
\hline 3 & $14.00-18.00$ & 6.010 & Kend & 1.128 & Kend \\
\hline 4 & $18.00-22.00$ & 981 & Kend & 862 & Kend \\
\hline Jumlah Total & 14.844 & Kend & 214 & Kend \\
\hline
\end{tabular}

Dari Tabel 1 dan Tabel 2 diperoleh jumlah volume puncak kendaraan roda 2 terjadi antara periode waktu pukul 10.00-14.00 pengamatan untuk ruas jalan KHA Dahlan dengan volume sebanyak 1.237 kendaraan dan periode waktu pukul 14.00-18.00 pengamatan untuk ruas jalan Diponegoro dengan volume sebanyak 6.010 kendaraan. Hal ini terlihat bahwa aktifitas yang tinggi di jalan diponegoro disebabkan oleh banyaknya pengguna kendaraan roda 2 yang melakukan aktifitas di perbelanjaan Gedung Pasar Aceh Baru, sedangkan aktifitas di ruas jalan KHA Dahlan disebabkan oleh pengguna kendaraan yang melakukan perbelanjaan di toko-toko disekitar Gedung Pasar Aceh Baru. Untuk volume puncak kendaraan roda 4 terjadi antara periode waktu pukul 10.00-14.00 pengamatan untuk ruas jalan KHA Dahlan dengan volume sebanyak 286 kendaraan dan juga periode waktu pukul 10.00-14.00 pengamatan untuk ruas jalan Diponegoro dengan volume sebanyak 1.128 kendaraan. 
Vol. 4 No.1 April 2018

pp. 1 - 11

\section{Akumulasi parkir kendaraan}

Akumulasi parkir adalah jumlah kendaraan yang masuk dikurangi dengan jumlah kendaraan yang keluar pada periode waktu tertentu ditambahkan dengan jumlah kendaraan yang parkir pada periode waktu sebelumnya. Dari survey dilapangan diperoleh :

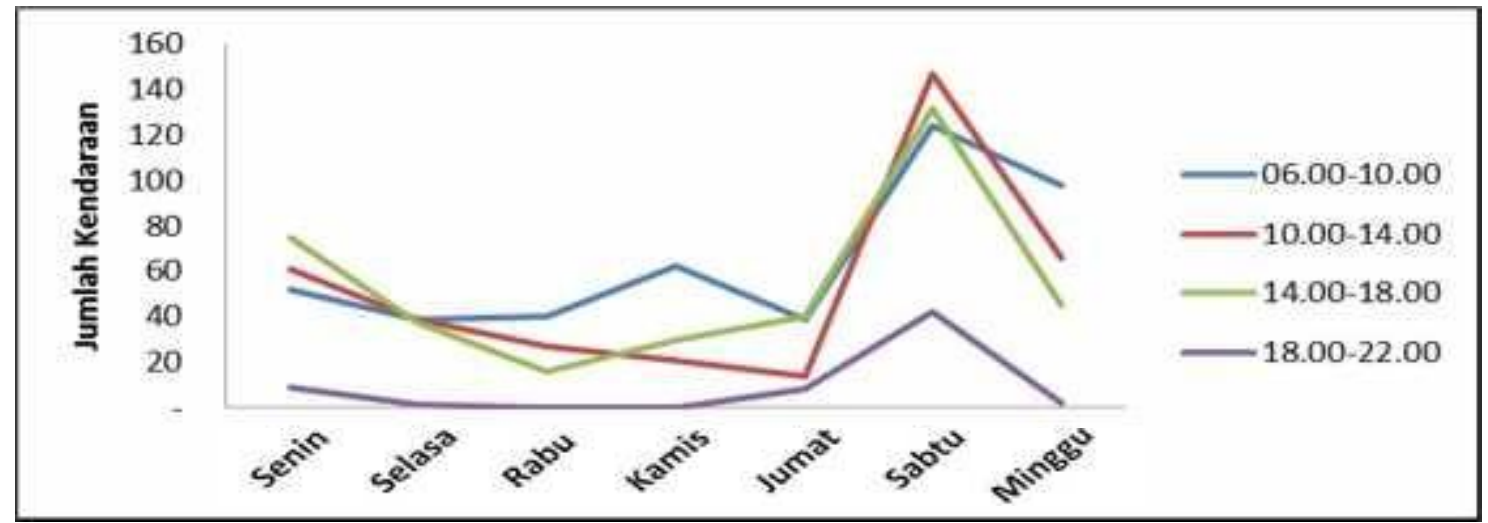

Gambar 2 Grafik Akumulasi Parkir Harian untuk Kendaraan Roda 2 pada Ruas Jalan KHA Dahlan

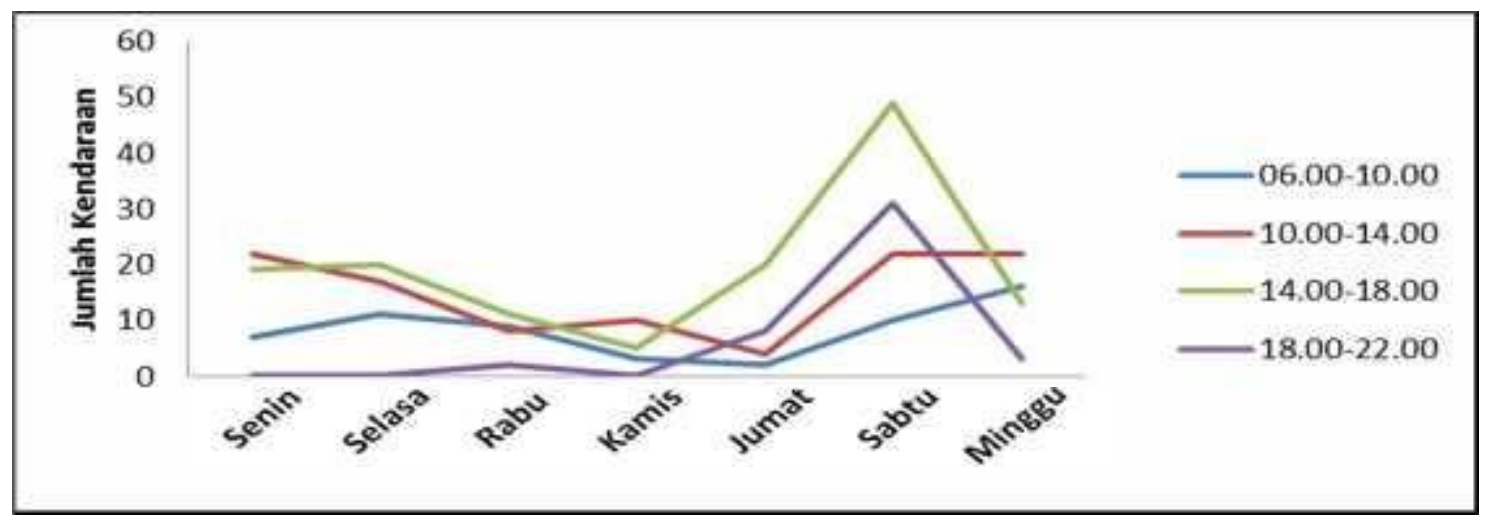

Gambar 3 Grafik Akumulasi Parkir Harian untuk Kendaraan Roda 4 pada Ruas Jalan KHA Dahlan

Pada Gambar 2 dan Gambar 3 diatas tingkat akumulasi tertinggi terjadi pada hari sabtu baik untuk kendaraan roda 2 maupun kendaraan roda 4, hal ini dikarenakan bahwa hari sabtu bukan merupakan hari kerja sehingga para pengunjung yang berbelanja di gedung pasar aceh baru banyak yang memarkirkan kendaraannya disekitar ruas jalan KHA Dahlan 
Vol. 4 No.1 April 2018

pp. 1 - 11

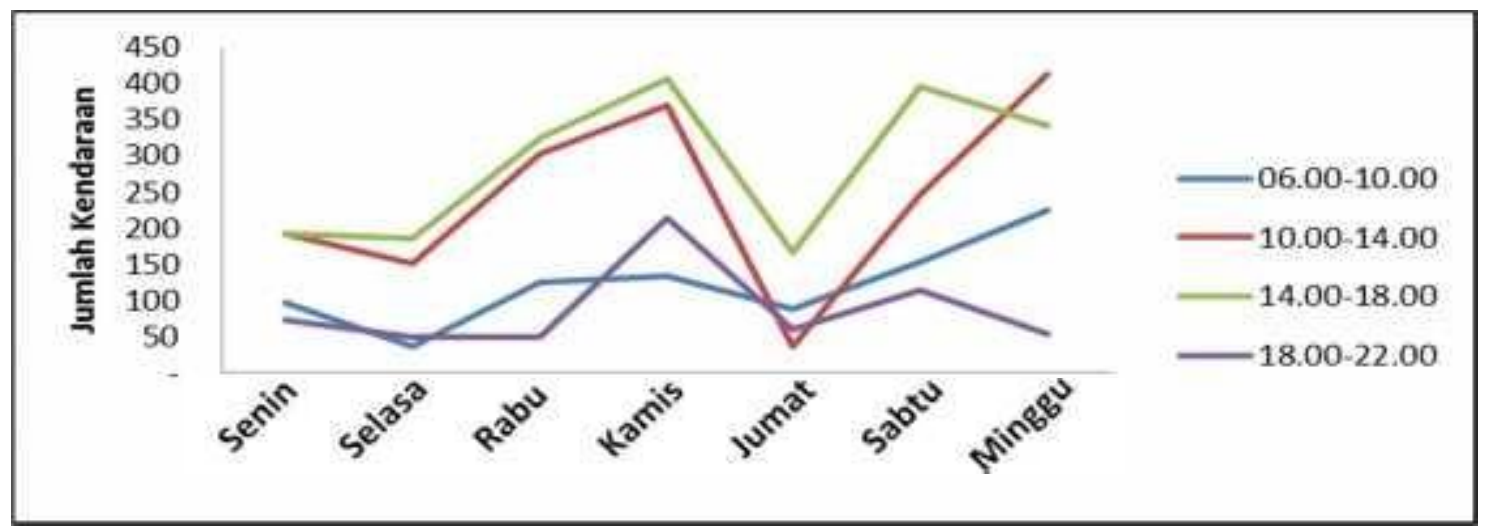

Gambar 4 Grafik Akumulasi Parkir Harian untuk Kendaraan Roda 2 pada Ruas Jalan Diponegoro

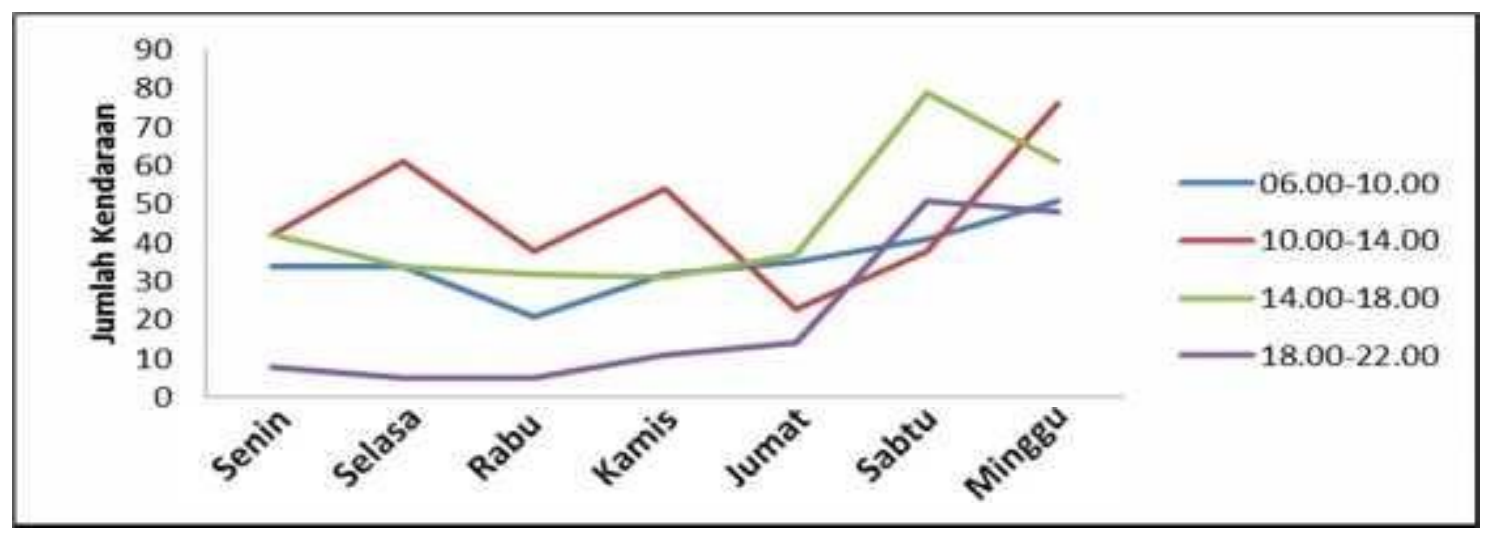

Gambar 5 Grafik Akumulasi Parkir Harian untuk Kendaraan Roda 4 pada Ruas Jalan Diponegoro

Sebaliknya untuk ruas jalan Diponegoro tingkat akumulasi tertinggi roda 2 terjadi pada hari minggu dan untuk roda 4 akumulasi tertinggi didapat di hari sabtu dan dapat dilihat dari Gambar 4 dan Gambar 5

\section{Pendapatan parkir}

Pendapatan parkir adalah penetapan harga parkir di suatu tempat tertentu. Biasanya pada kawasan yang ramai maka harga (tarif) parkir bisa menjadi lebih tinggi. Pendapatan parkir dihitung dengan

menggunakan

rumus

(1)

diperoleh 
Vol. 4 No.1 April 2018

pp. 1 - 11

Tabel 3 Pendapatan Parkir Rata-rata pada Ruas Jalan KHA Dahlan selama satu minggu

\begin{tabular}{|r|c|c|c|c|r|r|r|}
\hline \multirow{2}{*}{ No } & \multirow{2}{*}{ Waktu } & \multicolumn{2}{c}{$\begin{array}{c}\text { Kumlah } \\
\text { Ke ndaraan (Unit) }\end{array}$} & \multicolumn{2}{c}{$\begin{array}{c}\text { Duras i Rata-rata } \\
\text { (Jam/Ke nd) }\end{array}$} & \multicolumn{2}{c}{$\begin{array}{c}\text { Pe ndapatan Parkir } \\
\text { Rata-rata }\end{array}$} \\
& & Roda 2 & Roda 4 & Roda 2 & Roda 4 & Roda 2 & \multicolumn{1}{c|}{ Roda 4 } \\
\hline 1 & $06.00-10.00$ & 706 & 157 & 2,860 & 2,728 & 706.000 & 314.000 \\
\hline 2 & $10.00-14.00$ & 1.237 & 286 & 1,593 & 1,765 & 1.237 .000 & 572.000 \\
\hline 3 & $14.00-18.00$ & 979 & 280 & 2,023 & 2,029 & 979.000 & 560.000 \\
\hline 4 & $18.00-22.00$ & 143 & 28 & 1,117 & 1,071 & 143.000 & 56.000 \\
\hline \multicolumn{2}{|c|}{ Jumlah Total } & 3.065 & 751 & & & 3.065 .000 & 1.502 .000 \\
\hline
\end{tabular}

Tabel 4 Pendapatan Parkir Rata-rata pada Ruas Jalan Diponegoro selama satu minggu

\begin{tabular}{|c|c|c|c|c|c|c|c|}
\hline \multirow[t]{2}{*}{ No } & \multirow[t]{2}{*}{ Waktu } & \multicolumn{2}{|c|}{$\begin{array}{c}\text { Jumlah } \\
\text { Ke ndaraan (Unit) }\end{array}$} & \multicolumn{2}{|c|}{$\begin{array}{l}\text { Duras i Rata-rata } \\
\text { (Jam/Ke nd) }\end{array}$} & \multicolumn{2}{|c|}{$\begin{array}{c}\text { Pe ndapatan Parkir } \\
\text { Rata-rata (Rp) }\end{array}$} \\
\hline & & Roda 2 & Roda 4 & Roda 2 & Roda 4 & Roda 2 & Roda 4 \\
\hline 1 & $06.00-10.00$ & 2.064 & 469 & 2,985 & 2,764 & 2.064 .000 & 938.000 \\
\hline 2 & $10.00-14.00$ & 5.789 & 1.128 & 1,927 & 1,964 & 5.789 .000 & 2.256 .000 \\
\hline 3 & $14.00-18.00$ & 6.010 & 862 & 2,237 & 2,222 & 6.010 .000 & 1.724 .000 \\
\hline 4 & $18.00-22.00$ & 981 & 214 & 1,001 & 1,416 & 981.000 & 428.000 \\
\hline \multicolumn{2}{|c|}{ Jumlah Total } & 14.844 & 2.673 & & & 14.844 .000 & 5.346 .000 \\
\hline
\end{tabular}

Dari Tabel 3 diperoleh pendapatan parkir total pada ruas jalan KHA Dahlan selama satu minggu untuk kendaraan roda 2 sebesar Rp. 3.065.000,- dan untuk kendaraan roda 4 sebesar Rp. 1.502.000,-, sedangkan untuk Tabel 4 menunjukkan bahwa pendapatan parkir total pada ruas jalan Diponegoro selama satu minggu untuk kendaraan roda 2 sebesar Rp. 14.844.000,- dan untuk kendaraan roda 4 sebesar Rp. 5.346.000,-

\section{4. $\quad$ Net present value (NPV)}

Metode Net Present Value adalah metode yang berusaha membandingkan semua komponen biaya dan manfaat dari suatu proyek dengan acuan yang sama, agar dapat diperbandingkan satu dengan lainnya dengan tingkat discount rate yang akurat (5). Dalam hal ini yang diperhitungkan adalah nilai bersih sekarang baik nilai bersih biaya maupun nilai bersih manfaat. Apabila nilai bersih biaya sekarang lebih besar dari nilai bersih manfaat sekarang atau negatif (-) berarti bangunan atau investasi tersebut tidak layak (tidak menguntungkan) secara finansial dan apabila sebaliknya nilai bersih manfaat sekarang yang lebih besar dari nilai bersih biaya sekarang atau positif $(+)$ berarti bangunan atau investasi tersebut sangat layak (menguntungkan) secara finansial. Dengan menggunakan tingkat discount rate 10\%, 12\%, 15\% dan 18\%, maka hasil yang didapat dari tarif parkir menggunakan Qanun Kota Banda Aceh No 4 Tahun 2012 adalah : 
Tabel 5 Net Present Value (NPV)

\begin{tabular}{|c|c|c|c|}
\hline \multicolumn{4}{|c|}{ DISCOUNT RATE } \\
\hline $\mathbf{1 0 \%}$ & $\mathbf{1 2 \%}$ & $\mathbf{1 5 \%}$ & $\mathbf{1 8 \%}$ \\
\hline -Rp. 3.853.539.000,- & -Rp. 5.743.976.000,- & -Rp. 7.815.686.000,- & -Rp. 9.267.569.000,-- \\
\hline
\end{tabular}

Dari Tabel 5 diketahui bahwa tarif parkir menggunakan Qanun Kota Banda Aceh No 4 Tahun 2012 dengan tingkat discount rate 10\%, 12\%, 15\% dan 18\% semuanya negatif (-), artinya fasilitas parkir pada Gedung Pasar Aceh Baru tersebut tidak layak dibangun secara finansial.

\section{Benefit cost ratio (BCR)}

Metode Benefit Cost Ratio adalah metode yang mencari indeks yang menggambarkan tingkat efektifitas pemanfaatan biaya terhadap manfaat yang akan diperoleh. Metode ini sejalan dengan Metode Net Present Value (NPV), hanya saja indikator hasil yang didapatkan adalah apabila nilai bersih manfaat sekarang lebih kecil dari nilai bersih biaya sekarang, maka nilai $\mathrm{BCR}<1$ artinya bangunan atau investasi tersebut tidak layak (tidak menguntungkan) secara finansial dan sebaliknya apabila nilai bersih manfaat sekarang lebih besar dari nilai bersih biaya sekarang, maka nilai $\mathrm{BCR}>1$ artinya bangunan atau investasi tersebut sangat layak (menguntungkan) secara finansial. Dari analisis data diperoleh hasil :

Tabel 6 Benefit Cost Ratio (BCR)

\begin{tabular}{|l|l|l|l|}
\hline \multicolumn{4}{|c|}{ DISCOUNT RATE } \\
\hline $\mathbf{1 0 \%}$ & $\mathbf{1 2 \%}$ & $\mathbf{1 5 \%}$ & $\mathbf{1 8 \%}$ \\
\hline 0,809 & 0,706 & 0,584 & 0,493 \\
\hline
\end{tabular}

Dari Tabel 6 menunjukkan bahwa untuk tarif parkir menggunakan Qanun Kota Banda Aceh No 4 Tahun 2012 dengan tingkat discount rate 10\%, 12\%, 15\% dan 18\% diperolah BCR<1, artinya fasilitas parkir yang berada pada Gedung Pasar Aceh Baru tersebut tidak layak dibangun secara finansial.

\section{Internal rate of return (IRR)}

Metode IRR atau Internal Rate of Return, yaitu besaran yang menunjukkan nilai discount rate pada saat nilai $\mathrm{NPV}=0$ dan $\mathrm{BCR}=1$. Suatu investasi dikatakan layak secara finansial apabila nilai IRR $\geq$ dari tingkat suku bunga bank untuk investasi komersial sedangkan investasi dikatakan tidak layak secara finansial apabila nilai IRR < dari tingkat suku bunga bank untuk investasi komersial. Dari analisis perhitungan diperoleh hasil :

Tabel 7 Internal Rate of Return (IRR)

\begin{tabular}{|l|c|c|c|}
\hline \multicolumn{4}{|c|}{ DISCOUNT RATE } \\
\hline $\mathbf{1 0 \%}$ & $\mathbf{1 2 \%}$ & $\mathbf{1 5 \%}$ & $\mathbf{1 8 \%}$ \\
\hline \multicolumn{5}{|c|}{$-1,149 \%$} \\
\hline
\end{tabular}


Vol. 4 No.1 April 2018

pp. 1 - 11

Dari Tabel 7 diatas menunjukkan bahwa untuk tarif parkir menggunakan Qanun Kota Banda Aceh No 4 Tahun 2012 dengan tingkat discount rate 10\%, 12\%, 15\% dan 18\% diperolah bahwa fasilitas parkir Gedung Pasar Aceh Baru tidak layak dibangun secara finansial. Hal ini terlihat dari nilai IRR yang berada dibawah tingkat suku bunga bank untuk investasi komersial yaitu $\pm 15 \%$.

\section{Payback Period}

Payback Period adalah jangka waktu yang diperlukan untuk mengembalikan modal suatu investasi, dihitung dari aliran kas bersih (net) dimana dalam grafik dapat terlihat titik perpotongan antara komponen biaya (cost) dengan komponen manfaat (benefit). Dari analisis data diperoleh hasil :

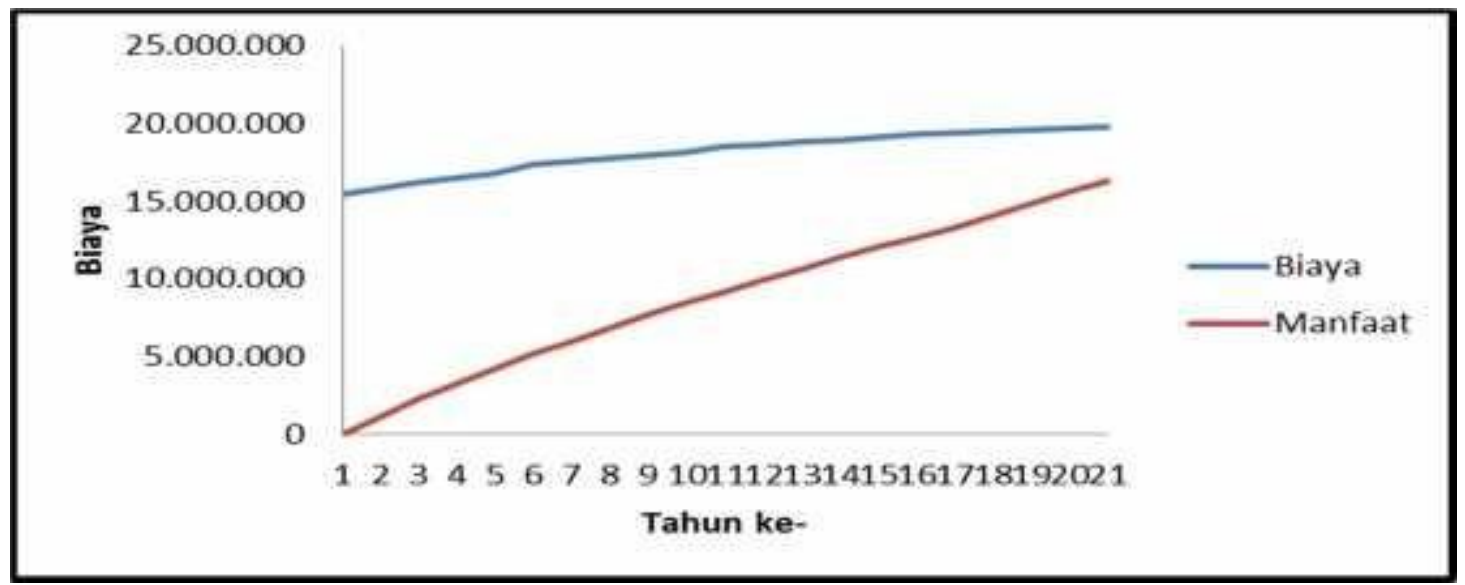

Gambar 6 Grafik Payback Period dengan Discount Rate 10\%

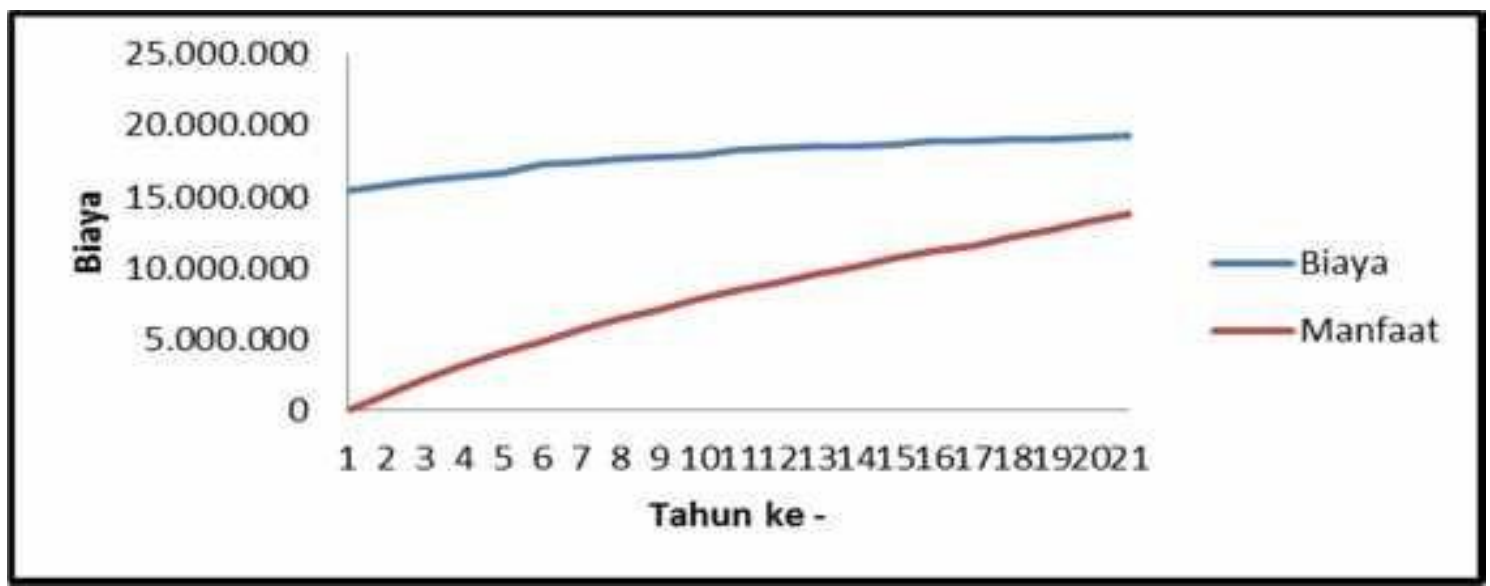

Gambar 7 Grafik Payback Period dengan Discount Rate 12\% 
Vol. 4 No.1 April 2018

pp. 1 - 11

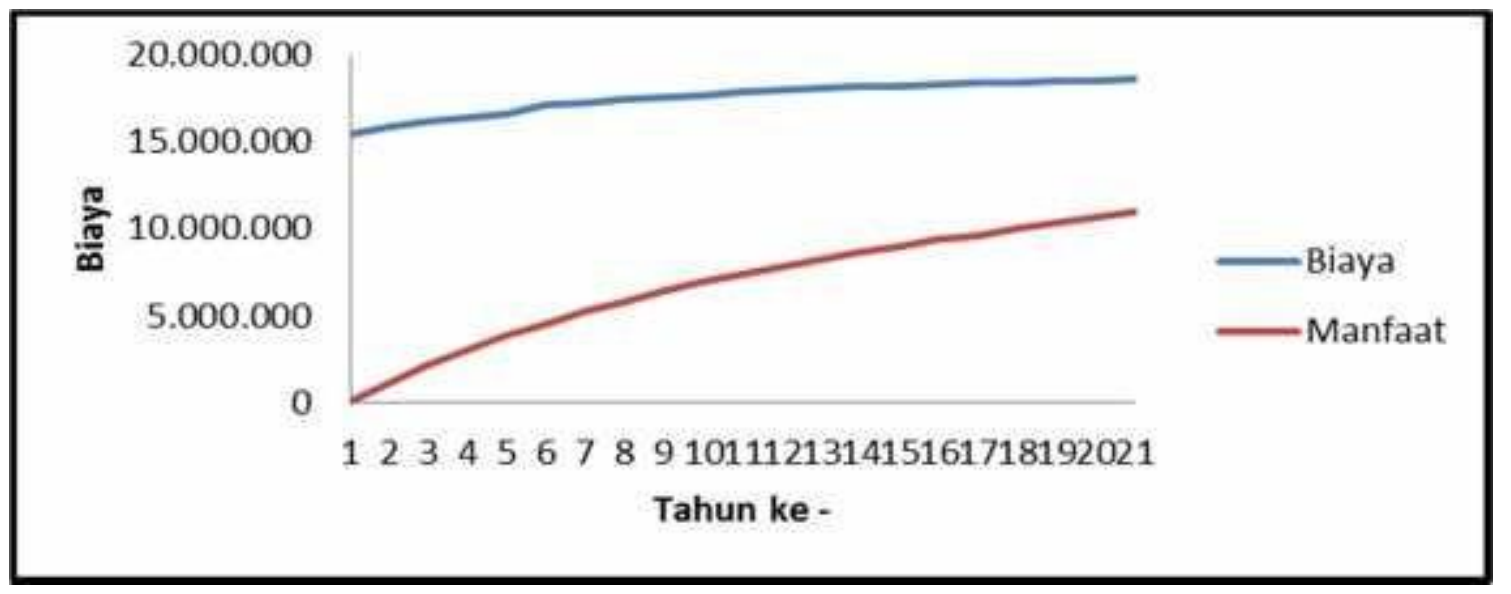

Gambar 8 Grafik Payback Period dengan Discount Rate 15\%

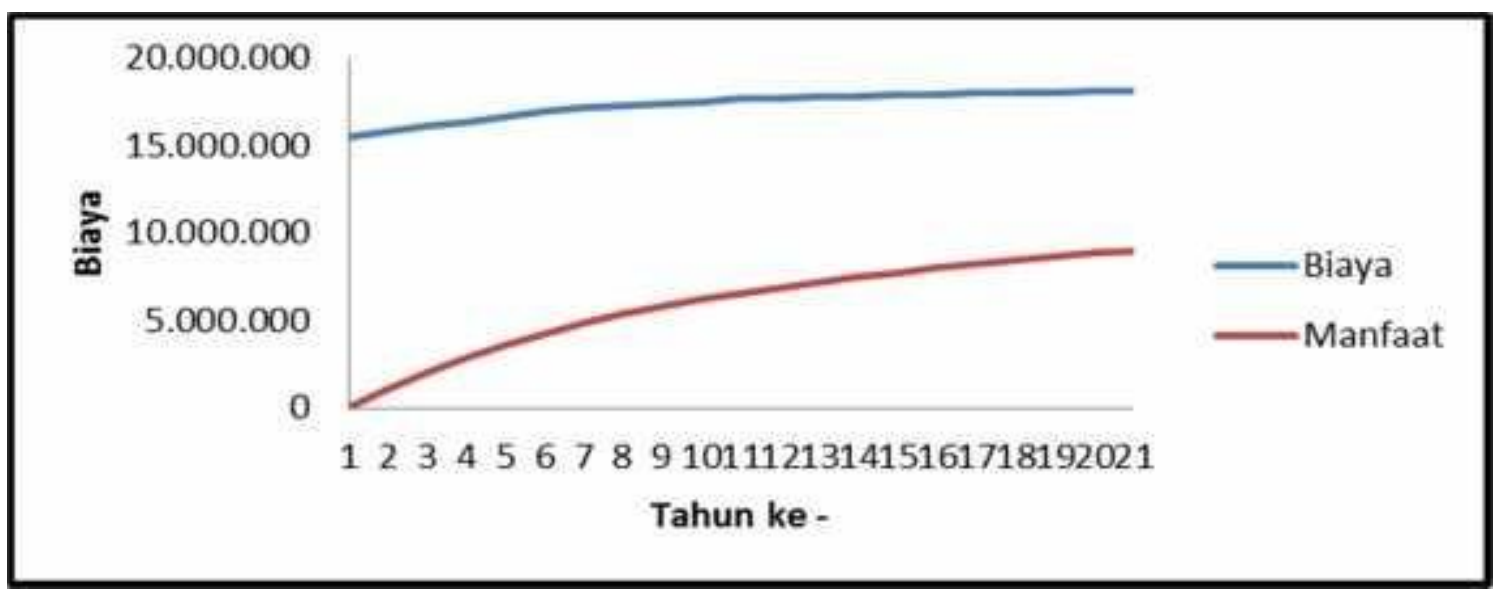

Gambar 9 Grafik Payback Period dengan Discount Rate 18\%

Dari gambar 6 s/d gambar 9 menunjukkan bahwa untuk tarif parkir menggunakan Qanun Kota Banda Aceh No 4 Tahun 2012 dengan discount rate 10\%, 12\%, 15\% dan 18\% pada grafik tidak terjadi perpotongan garis antara komponen biaya (cost) dengan komponen manfaat (benefit) artinya fasilitas parkir Gedung Pasar Aceh Baru tidak layak untuk dibangun secara finansial.

\section{KESIMPULAN}

Berdasarkan analisis data yang telah dihitung maka diperoleh kesimpulan :

1. Jumlah kendaraan roda 2 terbanyak yang parkir di kawasan Gedung Pasar Aceh Baru selama seminggu adalah 14.844 kendaraan dan jumlah kendaraan roda 4 terbanyak selama seminggu adalah 2.673 kendaraan yang terjadi pada ruas jalan Diponegoro;

2. Tingkat akumulasi parkir tertinggi kendaraan roda 2 terjadi pada hari sabtu dan minggu baik untuk kendaraan roda 2 maupun kendaraan roda 4;

3. Untuk semua tingkat discount rate menghasilkan nilai Net Present Value (NPV) negatif (-) dan nilai Benefit Cost Ratio (BCR) berada dibawah 1 atau BCR $<1$ sedangkan Internal Rate 
of Return (IRR) sebesar $-1,149 \%$ juga berada dibawah dari tingkat suku bunga bank untuk investasi komersial;

4. Tidak terjadi pengembalian (titik balik) modal karena semua tingkat discount rate $(10 \%, 12 \%, 15 \%$ dan $18 \%)$ tidak menghasilkan perpotongan antara nilai cost dan nilai benefit;

5. Untuk penggunaan sistem tarif parkir dengan menggunakan Qanun Kota Banda Aceh No 4 Tahun 2012 diperoleh bahwa fasilitas parkir Gedung Pasar Aceh Baru tersebut tidak layak dibangun secara finansial pada umur ekonomis konstruksi 20 tahun.

\section{SARAN}

1. Diharapkan kepada pengelola parkir Gedung Pasar Aceh Baru agar dapat menggunakan kebijakan tarif parkir dengan tarif parkir progresif agar dapat menghasilkan kelayakan secara finansial;

2. Diharapkan kepada pengelola parkir Gedung Pasar Aceh Baru agar dapat membangun fasilitas parkir pendukung disekitar Gedung Pasar Aceh Baru agar semua kendaraan yang berkunjung di sekitar kawasan Gedung Pasar Aceh dapat tertampung di fasilitas parkir dalam periode waktu tertentu.

\section{DAFTAR PUSTAKA}

[1] Tamin, Ofyar Z., 2000, Perencanaan dan Pemodelan Transportasi edisi ke 2, ITB, Bandung

[2] Khisty, Jotin C dan Lall, Kent B, 2003, Dasar-dasar Rekayasa Transportasi Jilid 2, Erlangga, Jakarta.

[3] Narendra Kasuma, I G., 2011, Analisis Kelayakan Finansial Rencana Pembangunan Gedung Parkir Bertingkat di Pasar Lokitasari, Universitas Udayana, Denpasar.

[4] Abubakar, I. Et al., 1998. Pedoman Perencanaan dan Pengoperasian Fasilitas Parkir, Direktorat Bina Sistem lalu Lintas dan Angkutan Kota Direktorat Jenderal Perhubungan Darat, Jakarta.

[5] LPKM-ITB, 1997, Modul Pelatihan, Studi Kelayakan Proyek Transportasi, Lembaga Pengabdian kepada Masyarakat ITB bekerjasama dengan Kelompok Bidang Keahlian Rekayasa Transportasi Jurusan ITB, Bandung. 